\title{
What do 15-year-olds really know about money?
}

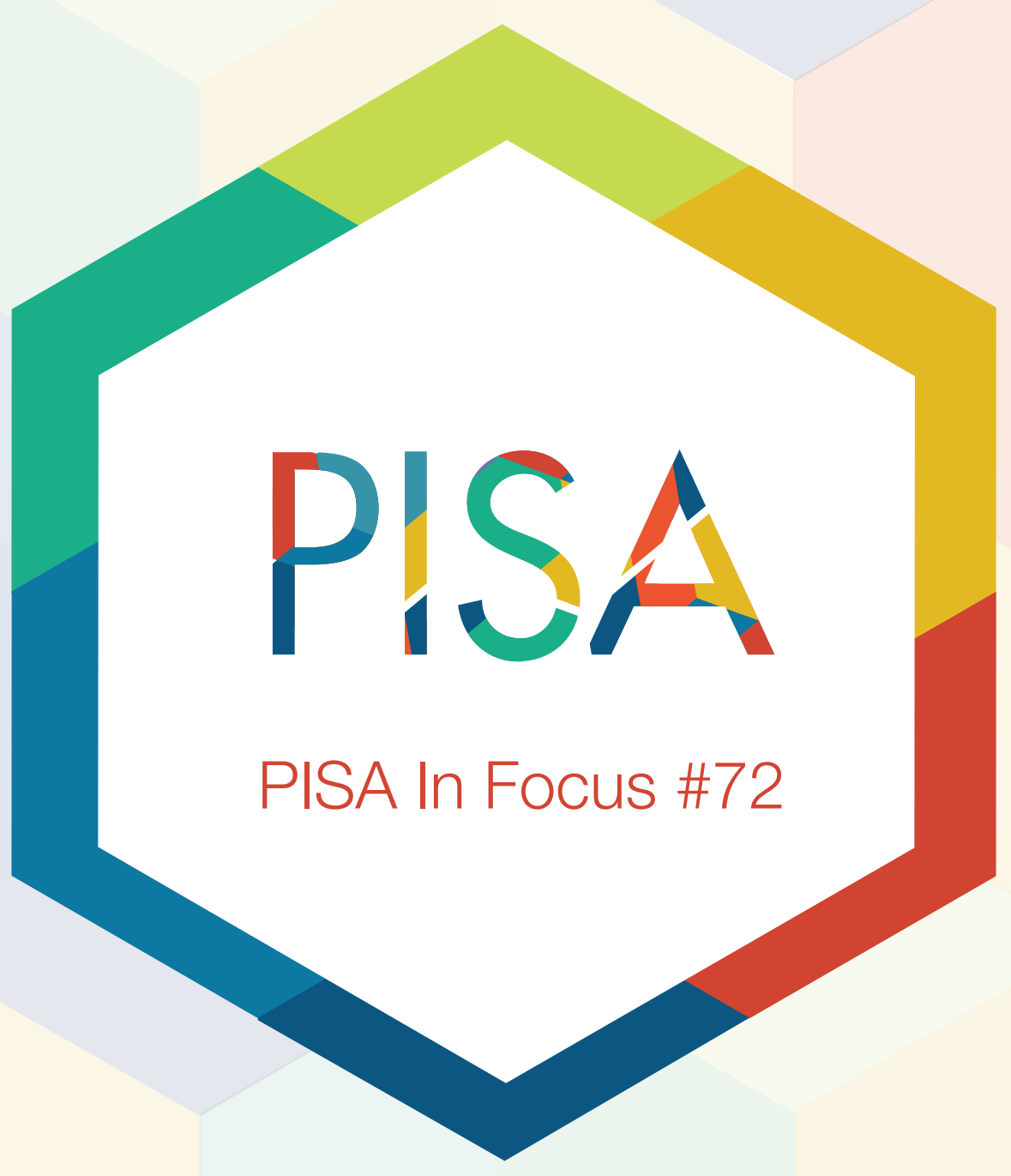




\section{What the data tell us}

\section{Student performance in financial literacy}

- Beijing-Shanghai-Jiangsu-Guangdong (China) (B-S-J-G [China]) outperforms all other participating countries/economies in financial literacy. The Flemish Community of Belgium, the participating Canadian provinces (British Columbia, Manitoba, New Brunswick, Newfoundland and Labrador, Nova Scotia, Ontario and Prince Edward Island), the Russian Federation, the Netherlands and Australia, in descending order of mean performance, have mean scores above the OECD average.

- Some $12 \%$ of students across OECD countries and economies are top performers in financial literacy, meaning that they are proficient at Level 5. These students can analyse complex financial products and solve non-routine financial problems. They show an understanding of the wider financial landscape, such as the implications of income-tax brackets, and can explain the financial advantages of different types of investments.

- On average across OECD countries and economies, $22 \%$ of students perform at or below Level 1 in financial literacy. The percentage of students performing at or below Level 1 is larger than $20 \%$ in Brazil, Chile, Lithuania, Peru, Poland, the Slovak Republic, Spain and the United States. These students can, at best, recognise the difference between needs and wants, make simple decisions about everyday spending, and recognise the purpose of everyday financial documents, such as an invoice.

- On average across the 10 participating OECD countries and economies, around 38\% of the variation in financial literacy scores reflects factors that are uniquely captured by the financial literacy assessment, while the remaining $62 \%$ of variation in financial literacy reflects skills that can be measured in the mathematics and/or reading assessments.

- In the Flemish Community of Belgium, Beijing-Shanghai-Jiangsu-Guangdong (China), the participating Canadian provinces and the Russian Federation, students perform better in financial literacy than students around the world who perform similarly in mathematics and reading. In contrast, students in Australia, Brazil, Chile, Italy, Lithuania, the Netherlands, Poland, the Slovak Republic and Spain perform worse than expected in financial literacy, based on the performance of students around the world in mathematics and reading.

\section{Percentage of students at each level of proficiency in financial literacy}

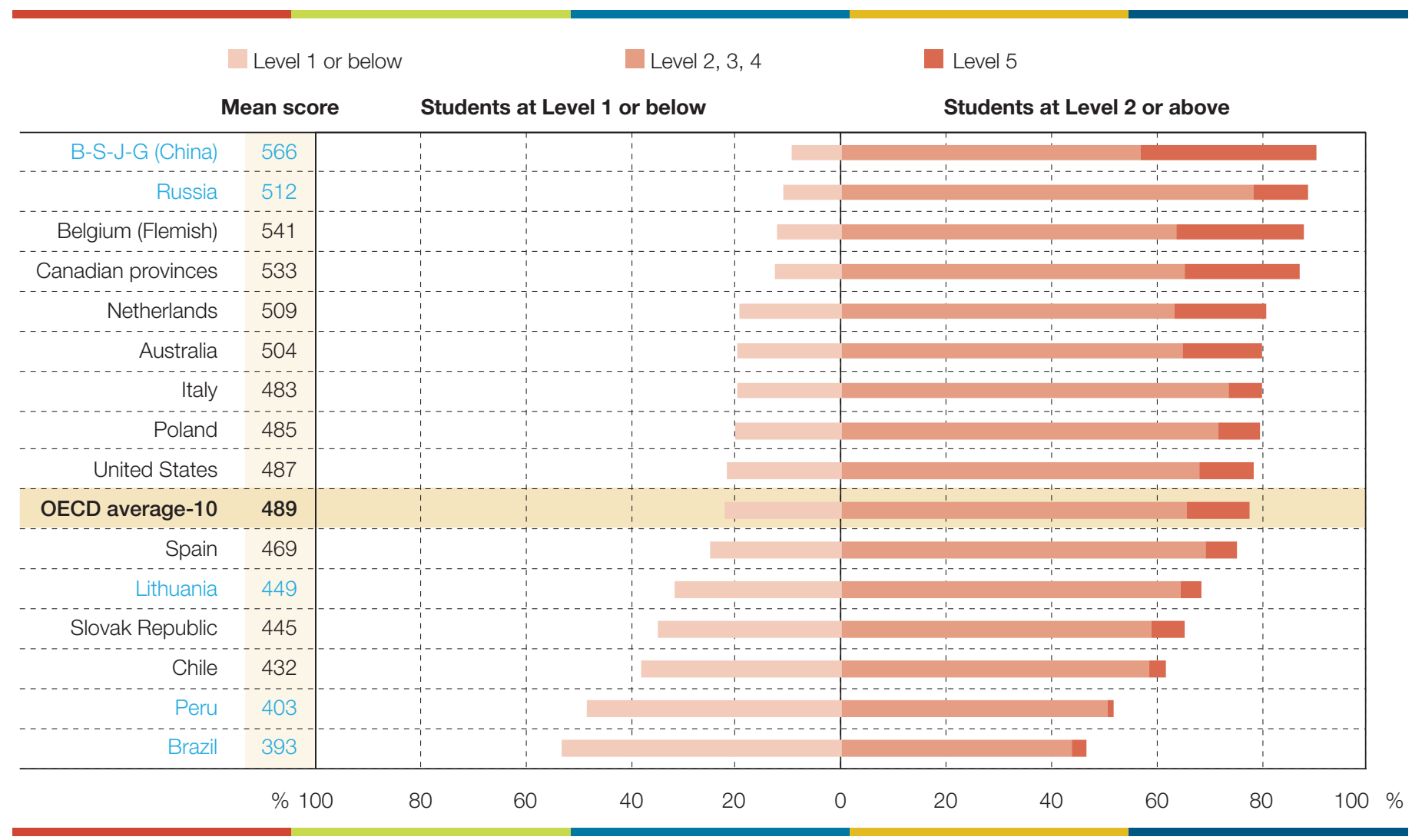

Countries and economies are ranked in descending order of the percentage of students who perform at or above Level 2. Source: OECD, PISA 2015 Database, Table IV.3.2. 


\section{How performance in financial literacy varies within countries and across student characteristics}

- Variation within each country/economy is wider than the variation observed between countries/economies at the mean. On average across OECD countries and economies, the gap between students scoring at the 90th percentile and those at the 10th percentile in financial literacy is 285 score points.

- Only in Italy do boys perform better than girls, by 11 score points, in financial literacy. By contrast, in Australia, Lithuania, Poland, the Slovak Republic and Spain, girls perform better than boys. In the remaining countries and economies, the difference in performance between boys and girls is not statistically significant. In 9 out of 15 countries and economies, more boys than girls are low performers.

- In 10 countries and economies with available data, socio-economically disadvantaged students are more likely than advantaged students to be low performers in financial literacy, after accounting for student performance in mathematics and reading and other characteristics. Advantaged students score 89 points higher than disadvantaged students, on average across OECD countries and economies, equivalent to more than one PISA proficiency level.

- Among countries and economies where at least 5\% of students have an immigrant background, the difference in financial literacy performance related to immigrant background is larger than 15 score points in the Flemish Community of Belgium, Italy, the Netherlands and Spain, after taking into account students' socio-economic status.

\section{Students' experience with money}

- In 10 out of 13 countries and economies with available data, discussing money matters with parents at least sometimes is associated with higher financial literacy than never discussing the subject, after taking into account students' socio-economic status.

- In Australia, the Flemish Community of Belgium, the participating Canadian provinces and the Netherlands, more than $70 \%$ of students hold a bank account, while in Chile, Italy, Lithuania, Poland and the Russian Federation, fewer than $40 \%$ of students do.

- In Australia, the Flemish Community of Belgium, the participating Canadian provinces, Italy, the Netherlands, Spain and the United States, students who hold a bank account perform better in financial literacy - by over 20 score points - than students of similar socio-economic status who do not have a bank account.

\section{Relative performance in financial literacy \\ Difference between the actual financial literacy score and the score predicted by students' performance in mathematics and reading}

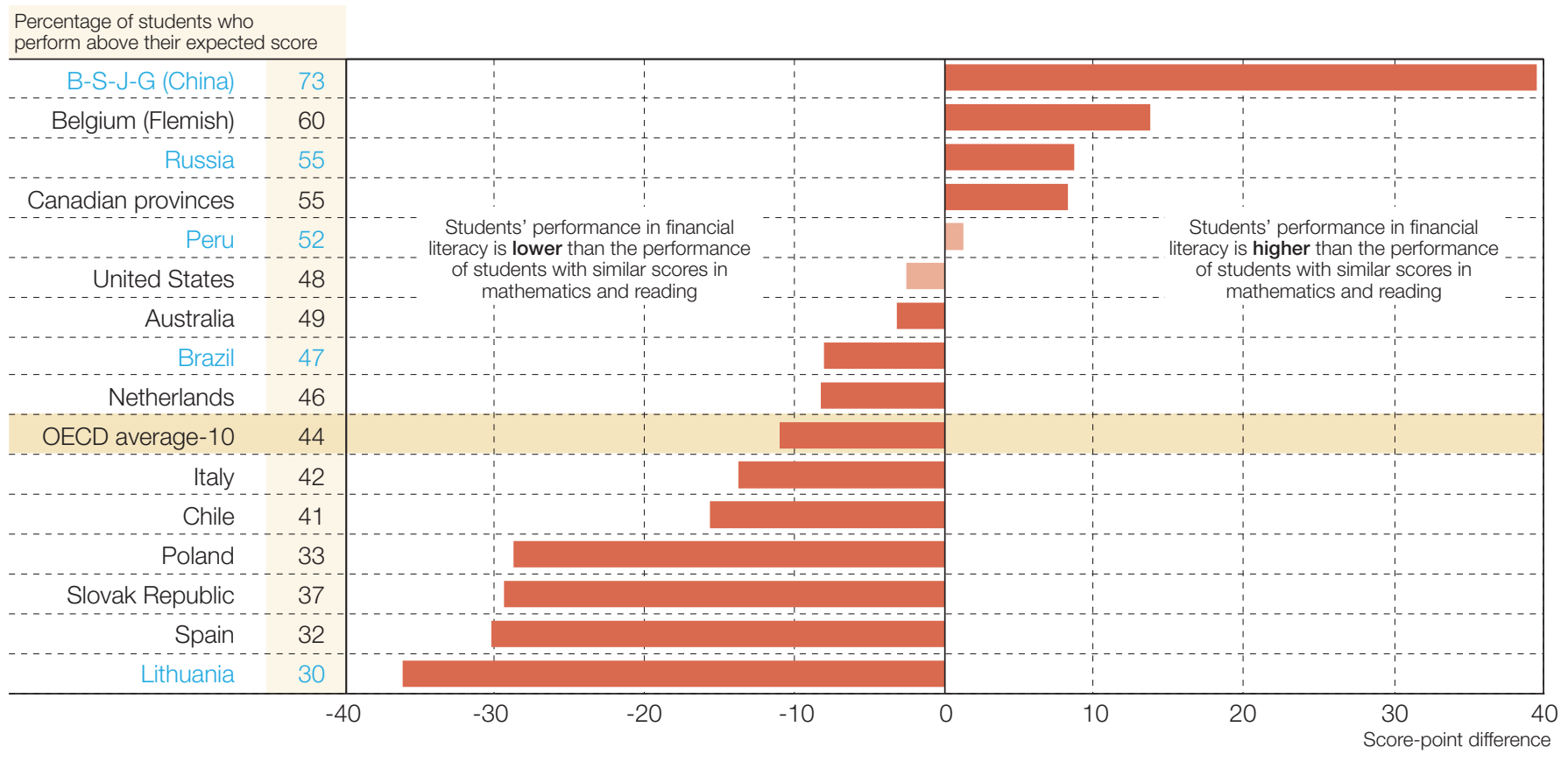

Note: Statistically significant differences are shown in a darker tone.

Countries and economies are ranked in descending order of the score-point difference between actual and expected performance.

Source: OECD, PISA 2015 Database, Table IV.3.11. 
- Gifts of money are the most frequent source of money for 15 -year-old students. Over $80 \%$ of students in 9 countries and economies out of 13 with available data receive money in the form of gifts. More than one in three students, on average in each country/economy, reported that they receive money from an allowance or pocket money for regularly doing chores at home. On average across OECD countries and economies, 64\% of students earn money from some formal or informal work activity, such as working outside school hours, working in a family business, or doing occasional informal jobs.

- On average across OECD countries and economies, students who receive gifts of money score 13 points higher in financial literacy than students who do not, after taking into account performance in mathematics and reading, and various student characteristics, including socio-economic status.

\section{Students' financial literacy, behaviour and expectations}

- At least $50 \%$ of students, on average, in each of the 13 countries and economies with available data, reported that they would save if they want to buy something for which they do not have enough money.

- On average across OECD countries and economies, when asked what they would do if they want to buy something for which they do not have enough money, students who perform at Level 4 or 5 in financial literacy are about three times as likely as students performing at or below Level 1 with similar characteristics and performance in core PISA subjects to report that they would save, rather than reporting that they would buy the item anyway with money that should be used for something else.

- In Australia, Chile, Italy, Lithuania, Peru and Spain, students performing at Level 4 or above in financial literacy were at least $70 \%$ more likely than students performing at or below Level 1 to report that they expect to complete university education, after taking into account socio-economic status, performance in mathematics and reading, and other student characteristics.

\section{Mean performance in financial literacy, by students' socio-economic status}

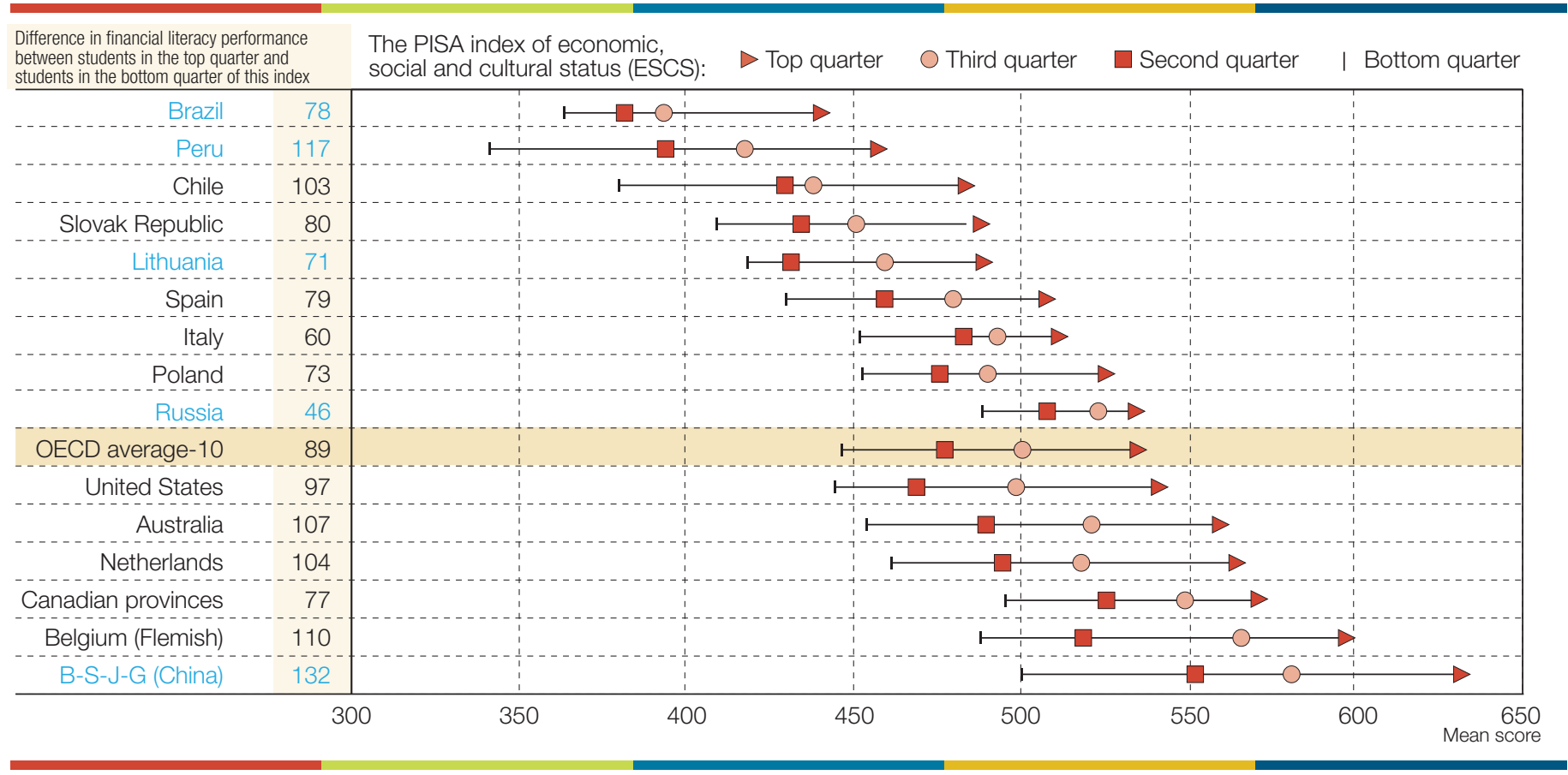

Countries and economies are ranked in descending order of the mean score of advantaged students.

Source: OECD, PISA 2015 Database, Table IV.4.11.

\section{As globalisation and digital technologies have made financial services more widely accessible and challenging, and as financial decisions are increasingly common in the lives of young people, everyone needs to be financially literate}

Globalisation and digital technologies have made financial services and products more widely accessible and at the same time more complex to handle. Responsibility for investing in higher education or planning for retirement is increasingly assumed by individuals. Young people are now more likely to encounter situations where they need to set their spending priorities, be aware of new types of fraud, know that some items that they want to buy will incur ongoing costs, and be alert that some purchasing offers are simply too good to be true. 
On average across OECD countries and economies, as many as 22\% of students perform below Level 2 in financial literacy, which can be considered the baseline level of proficiency that is required to participate in society. Perhaps unsurprisingly, disadvantaged students are over-represented among low performers. Financial literacy is relevant not just for those who have large sums of money to invest; everyone needs to be financially literate, especially those who live on tight budgets and have little leeway in case they make financial mistakes.

While disadvantaged students are among the least financially literate, they probably need some financial knowledge and skills the most. Large disparities in skills among 15-year-olds signal that not all students are offered an equal opportunity to develop their financial literacy. If socio-economic disparities are not addressed early, they are likely to lead to even larger gaps in financial literacy as students become adults. Low-performing disadvantaged students need to be supported to ensure that they can safely navigate the (increasingly digital) financial system as they become more independent.

\section{Students should be helped to make the most of learning opportunities in school}

Financial literacy performance is strongly correlated with performance in mathematics and reading, even though a significant part of the skills tested in this assessment are unique to financial literacy. Students should be helped to make the most of what they learn in subjects taught in compulsory education, which could also be complemented with more specific financial literacy content. Several countries have started integrating some financial literacy topics into existing school subjects, such as mathematics or social sciences. However, more evidence is needed to show the extent to which incorporating financial literacy elements into existing subjects is effective as compared to other approaches to improve students' levels of financial literacy.

Fostering the development of financial literacy skills in school could also be a way to offer students learning opportunities beyond those provided by parents and peers, to help overcome socio-economic inequalities, and to expose students to more balanced messages than those they might receive through media and advertising.

\section{Students are likely to develop their financial skills through direct experience, and they should be provided with safe opportunities to "learn by doing" outside of school}

Evidence that there is a positive relationship between performance in financial literacy and holding a bank account or receiving gifts of money might suggest that some kind of experience with money or financial products could provide students with an opportunity to reinforce financial literacy, or that students who are more financially literate are more motivated to use financial products. Parents are very likely to be involved in these experiences, as they may have given their children money through allowances or gifts, opened a bank account for them and taught them how to use it.

\section{Performance in financial literacy, by whether students hold a bank account} Score-point difference between students who hold a bank account and those who do not

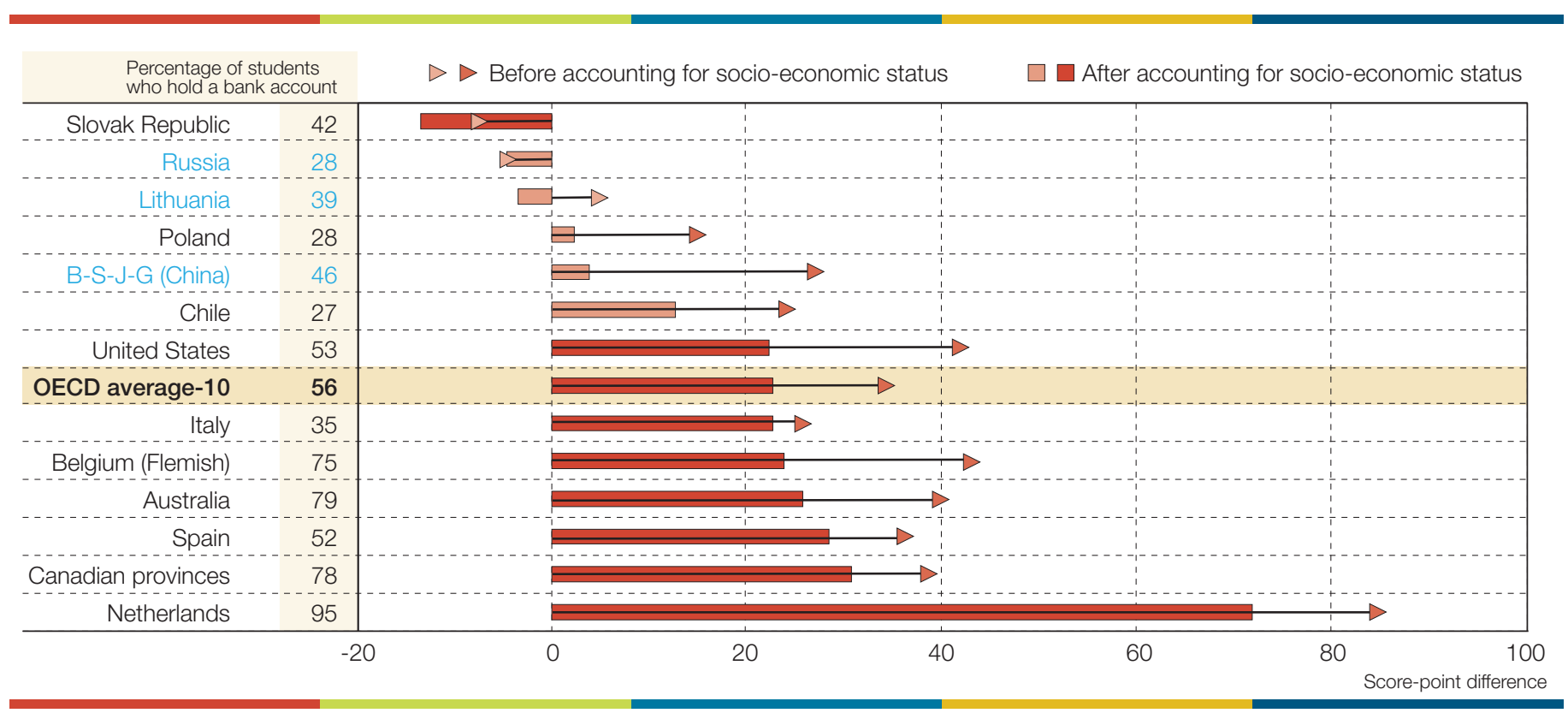

Note: Score-point differences that are statistically significant are marked in a darker tone.

Countries and economies are ranked in ascending order of the score-point difference between students who hold a bank account and students who do not, after accounting for socio-economic status.

Source: OECD, PISA 2015 Database, Tables IV.5.8 and IV.5.13. 


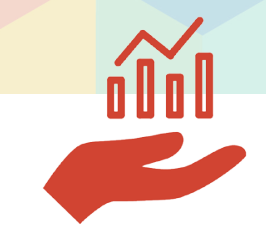

Even under the supervision of parents, it is important that young people can access financial products and services that are safe and regulated, and that they start to have an understanding of the risks associated with the different products and services, so that they can safely approach the financial system even before they acquire full legal rights to enter into financial contracts by themselves.

Young people can be further supported to "learn by doing" through after-school initiatives, such as videos, competitions, interactive tools and serious games - via digital and/or traditional platforms. These initiatives are used not so much to disseminate information but to provide young people with applied knowledge and allow them to safely experience financial situations and decisions before they encounter them in real life.

\section{As parents are crucial in helping their children acquire and develop financial attitudes, habits, knowledge and skills, they should be targeted at the same time as young people}

What students know about financial literacy depends to a large extent on their parents and families, both in terms of the resources that they make available to them and through direct engagement. In all countries and economies with available data, more than one in two students reported that they discuss money matters with their parents on a weekly or monthly basis. In 10 countries and economies, discussing money matters with parents is associated with higher financial literacy than never discussing the subject, even after taking into account students' socio-economic status.

While developing policies and initiatives aimed directly at improving the financial literacy of young people, countries should continue to strengthen their initiatives targeting adults, particularly disadvantaged adults, through national strategies for financial education. Engaging parents and families is a way of targeting one of the most important sources of learning for young people, and it can complement what young people learn from other sources. 


\section{For more information}

Contact: Chiara Monticone (Chiara.Monticone@oecd.org)

See: OECD (2017), PISA 2015 Results (Volume IV): Students' Financial Literacy, OECD Publishing, Paris, http://dx.doi.org/10.1787/9789264270282-en.

Coming next month: Do students spend enough time on learning?

This paper is published under the responsibility of the Secretary-General of the OECD. The opinions expressed and the arguments employed herein do not necessarily reflect the official views of OECD member countries.

This document and any map included herein are without prejudice to the status of or sovereignty over any territory, to the delimitation of international frontiers and boundaries and to the name of any territory, city or area.

This work is available under the Creative Commons Attribution-NonCommercial-ShareAlike 3.0 IGO (CC BY-NC-SA 3.0 IGO). For more detalied information regarding the scope and terms of the licence as well as possible commercial use of this work or the use of PISA data please consult Terms and Conditions at www.oecd.org. 
Visit :

www. oecd.org/pisa

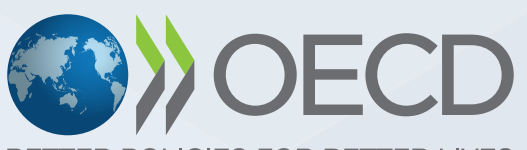

BETTER POLICIES FOR BETTER LIVES 